\title{
三次元暁角法の公式による円弧部材を含む 立体ラーメンの解法
}

正会員牧野稔*

§1，序曲線材在含さラーメン化関する研究㤝、 これまで数多く発表されているが、乙れらは取扱う曲楾 の性質によつて二種類に分類される。その一つ泣曲線材 の曲率が一つの場合で、円弧とか、パラボラ、山型材な

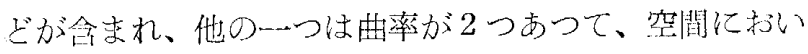
て部材が㹉れている、らせん階段など老考光るものであ る。もつとも後者の場合には、亦だてれをラーメン内の 部材として取㧙つている例はない上うである。将米、航 罙機、車粫等の分野にこの上うな問題があるかも知れな いが、こつでは建築に一般にあらわれる曲線材の例とし て、円弧部材をとり、これに三次元揬角法の公式の誘導

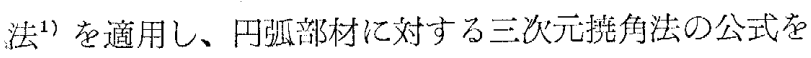
求め、立体ラーメン内の部材として取报う方法を述べる ことにする。

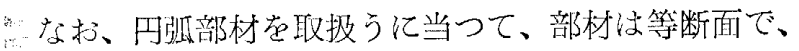
曲率はあまり大きくなく、したがつて円弧部材の微小部 分に対しては、直線材の理論が成立するものとし、せん 断変形の影響求よび曲率変化の影響はてれを省は略して、 諸係数在求わることにしよう。

\section{§ 2. 円弧部材に対する三次元撓角法公式の誘導}

こ〉で取扯う円弧部材は、その断面の主軸の一つが、 円谜の中心を通るものとする。そして部材の微小部分に 扔いて、これを $\alpha_{1}$ 軸とし、切線方向に $\gamma_{1}$ 軸芭とり、 これらに直角に $\beta_{1}$ 軸を右手系の直角座標軸を形成する ように定めるものとする。円弧部材の位置は、この部材 の两端を結ふ置換梁在基準として考学るととにし、第 1 図に示すように一端A $\mathrm{A} り$ 他端 $\mathrm{B}$ えの方向在 $r$ 軸とし、 またこれ机直角に师弧の内側向つて、円弧の平面内に

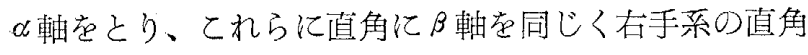
來慓軸を形成するように定めるものとする。このように すると、いま述べた二つの座標軸は部材上の位置の函数 で結ばれることになり、また空間に固定する $X Y Z$ 軸と は、座標変換の作用素で結合されることになる。

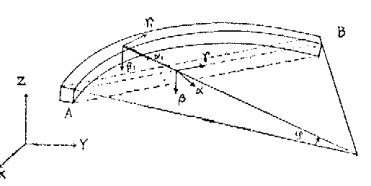

第1図 円弧部材に扮け名

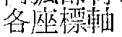

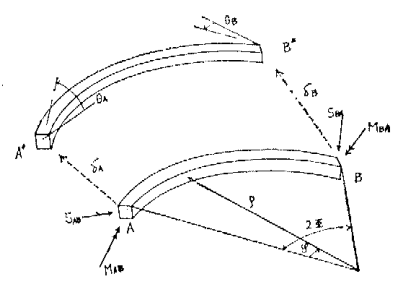

第 2 図

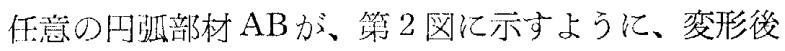
$\mathrm{A}^{\prime} \mathrm{B}^{\prime}$ 亿移動したとする。内坬の半径をの、その半開角 在すとすると、Aより $\varphi$ の角废の位置に抒ける断面の応 力は、部材の材端モーメントおよび材端力の正の方向を、 節点より作用する方向として、A 端の材端モーメント $M_{A B} お$ おび材端力 $S_{A B} の \alpha \beta r$ 軸党の成分之中間荷重 つ影響量で次のようになる。

$$
\begin{aligned}
& \left.M_{\alpha 1}(\varphi)=M_{A B \alpha} \cos (\varphi-\Phi)-M_{A B \gamma} \sin (\varphi-\Phi)\right) \\
& +S_{A B \beta} \rho \sin \varphi+M_{\alpha 1}^{\varphi} \\
& M_{\beta_{1}}(\varphi)=M_{A B \beta}-S_{A B \alpha} \rho\{\sin \Phi+\sin (\varphi-\Phi)\} \\
& -S_{A B_{\gamma}} \rho\{\cos (\varphi-\Phi)-\cos \varphi\}+M_{\beta_{1}}^{\varphi} \\
& M_{\gamma 1}(\varphi)=M_{A B_{\gamma}} \cos (\varphi-\Phi)+M_{A B \alpha} \sin (\varphi-\Phi) \\
& +S_{A B \beta} \rho(1-\cos \varphi)+M_{r 1}^{\varphi} \\
& Q_{\alpha 1}(\varphi)=S_{A B \alpha} \cos (\varphi-\Phi)-S_{A B \gamma} \sin (\varphi-\Phi) \\
& +W_{\alpha 1}{ }^{\varphi} \\
& Q_{\beta 1}(\varphi)=S_{A B \beta}+W_{\beta 1}^{\varphi} \\
& \begin{aligned}
N_{\gamma 1}(\varphi)= & -S_{A B \gamma} \cos (\varphi-\Phi)-S_{A B \alpha} \sin (\varphi-\Phi) \\
& +W_{\gamma_{1}}{ }^{\varphi}
\end{aligned}
\end{aligned}
$$
および $r$ 軸に対する成分を表わし、 $\alpha_{1} \beta_{1} \gamma_{1}$ のサフィック 久は部材の断面の主軸住対する成分とする。また $M_{\alpha 1}{ }^{\varphi}$ $M_{\beta 1}{ }^{\varphi} M_{\gamma 1}{ }^{\varphi}$ および $W_{\alpha 1}{ }^{\varphi} W_{\beta 1}{ }^{\varphi} W_{\gamma 1}{ }^{\varphi}$ は中間荷重によ つて生ずる $\varphi$ の位置でのモーメント、せん断力および軸 方向力の $\alpha_{1} \beta_{1} r_{1}$ 軸汇関する成分圭示すものである。

円弧部材においても，せ九断力の影響や曲率変化の影 響は小さいととが知られている2)ので、これらの項を省 略すれば、この部材に貯学られる歪エネルギーは、変形 が小さいという条件より、応力の二次同次式で、

$$
u=\frac{1}{2 E I_{\alpha 1}} \int_{0}^{2 \Phi}\left\{M_{\alpha 1}(\varphi)\right\}^{2} \rho d \varphi+\frac{1}{2 E I_{\beta 1}} \int_{0}^{2 \Phi}\left\{M_{\beta 1}(\varphi)\right\}^{2} \rho d \varphi+\frac{1}{2 G J} \int_{0}^{2 \Phi}\left\{M_{\gamma_{1}}(\varphi)\right\}^{2} \rho d \varphi+\frac{1}{2 E A} \int_{0}^{2 \Phi}\left\{N_{\gamma_{1}}(\varphi)\right\}^{2} \rho d \varphi
$$

と表わされる。て〉にEI $I_{\alpha 1}$ および $E I_{\beta 1}$ は $\alpha_{1}$ および

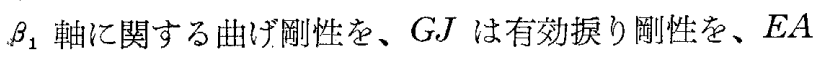
は軸方向力に関する用性を示するのとする。

\footnotetext{
* 建設省建築研究所 研究員
}

A 端の応力で (2) 式老微分すると、乙れらは耐材端の 相対変形に等しいので、材端角変化を $\theta$, 村端変位を $\delta$ で表わせば、次のように整理するてとができる。てのと き $L \mathrm{AB}$ 間の距離とする。 
$\left(\begin{array}{l}\theta_{A \alpha}-\theta_{B \alpha} \\ \theta_{A \beta}-\theta_{B \beta} \\ \theta_{A \gamma}-\theta_{B \gamma} \\ \delta_{A \alpha}-\delta_{B \alpha}+L \theta_{B \beta} \\ \delta_{A \beta}-\delta_{B \beta}-L \theta_{B \alpha} \\ \delta_{A_{\gamma}}-\delta_{B_{\gamma}}\end{array}\right)=\left(\begin{array}{cccccc}\frac{L}{E I_{\alpha 1}}\left(\boldsymbol{A}+\tau_{\alpha} \boldsymbol{C}\right) & 0 & 0 & 0 & \frac{L^{2}}{E I_{\alpha 1}}\left(\boldsymbol{E}+\tau_{\alpha} \boldsymbol{F}\right) & 0 \\ 0 & \frac{L}{E I_{\beta 1}} \boldsymbol{O} & 0 & -\frac{L^{2}}{E I_{\beta 1}} \boldsymbol{J} & 0 & -\frac{L^{2}}{E I_{\beta 1}} \boldsymbol{K} \\ 0 & 0 & \frac{L}{G J}\left(\boldsymbol{A}+\frac{1}{\tau_{\alpha}} \boldsymbol{C}\right) & 0 & \frac{L^{2}}{E I_{\alpha 1}}\left(\tau_{\alpha} \boldsymbol{G}-\boldsymbol{D}\right) & 0 \\ -\frac{L^{2}}{E I_{\beta 1}} \boldsymbol{J} & 0 & 0 & \frac{L^{3}}{E I_{\beta 1}}\left(\boldsymbol{L}+\frac{I_{\beta 1}}{A L^{2}} \boldsymbol{C}\right) & 0 & \frac{L^{3}}{E I_{\beta 1}} \boldsymbol{N} \\ \frac{L^{2}}{E I_{\alpha 1}}\left(\boldsymbol{E}+\tau_{\alpha} \boldsymbol{F}\right) & 0 & \frac{L^{2}}{E I_{\alpha 1}}\left(\tau_{\alpha} \boldsymbol{G}-\boldsymbol{D}\right) & 0 & \frac{L^{3}}{E I_{\alpha 1}}\left(\boldsymbol{H}+\tau_{\alpha} \boldsymbol{I}\right) & 0 \\ 0 & -\frac{L^{2}}{E I_{\beta 1}} \boldsymbol{K} & 0 & -\frac{L^{3}}{E I_{\beta 1}} \boldsymbol{N} & 0 \frac{L^{3}}{E I_{\beta 1}}\left(\boldsymbol{M}+\frac{I_{\beta 1}}{A L^{2}} \boldsymbol{A}\right)\end{array}\right)\left(\begin{array}{l}M_{A B \alpha} \\ M_{A B \beta} \\ M_{A B_{\gamma}} \\ S_{A B \alpha} \\ S_{A B \beta} \\ S_{A B_{\gamma}}\end{array}\right)+\left(\begin{array}{l}F^{\prime}{ }_{A B \alpha} \\ F_{A B \beta}^{\prime} \\ F_{A B \gamma}^{\prime} \\ G_{A B \alpha}^{\prime} \\ G_{A B \beta}^{\prime} \\ G_{A B \gamma}^{\prime}\end{array}\right)$

て〉に $\tau_{\alpha}=\frac{E I_{\alpha 1}}{G J}$ で、断面の形状によつて決る值となり、A, $G, \cdots \cdots \cdots O$ の係数な円弧の開角のみの函数で表わ されるものとなる。例えば $\boldsymbol{A}=\frac{1}{2}\left\{\frac{\Phi}{\sin \Phi}+\cos \Phi\right\}$ である。

$K_{0}$ を標準剛度として $\frac{E I_{\alpha 1}}{L}=K_{0} k_{\alpha}, \frac{E I_{\beta 1}}{L}=K_{0} k_{\beta}, \frac{G J}{L}=K_{0} k_{r}, E A L=K_{0} k_{n}$ と惪き、(3) 式を変換して、材端も ーメントおよご材端力を村端変形量で表わし、三次の行列の式に分解すると、

$$
\begin{aligned}
& {\left[\begin{array}{l}
M_{A B \alpha} \\
M_{A B \beta} \\
M_{A B_{\gamma}}
\end{array}\right]=K_{0}\left\{\left[\begin{array}{ccc}
\lambda_{11} k_{\alpha} & 0 & \lambda_{31} k_{\alpha} \\
0 & \lambda_{22} k_{\beta} & 0 \\
\lambda_{31} k_{\alpha} & 0 & \lambda_{33} k_{\gamma}
\end{array}\right]\left[\begin{array}{c}
\theta_{A \alpha} \\
\theta_{A \beta} \\
\theta_{A \gamma}
\end{array}\right]+\left[\begin{array}{ccc}
\lambda_{11}^{\prime} k_{\alpha} & 0 & -\lambda_{31} k_{\alpha} \\
0 & \lambda^{\prime} k_{22} k_{\beta} & 0 \\
\lambda_{31} k_{\alpha} & 0 & -\lambda_{33} k_{\gamma}
\end{array}\right]\left[\begin{array}{c}
\theta_{B \alpha}{ }^{-} \\
\theta_{B \beta} \\
\theta_{B \gamma}
\end{array}\right]\right.} \\
& \left.-\frac{1}{L}\left[\begin{array}{ccc}
0 & -\lambda^{\prime \prime}{ }_{11} k_{\alpha} & 0 \\
\lambda^{\prime \prime}{ }_{22} k_{\beta} & 0 & \lambda^{\prime \prime}{ }_{23} k_{\beta} \\
0 & -2 \lambda_{31} k_{\alpha} & 0
\end{array}\right]\left[\begin{array}{c}
\delta_{B \alpha}-\delta_{A \alpha} \\
\delta_{B \beta}-\delta_{A \beta} \\
\delta_{B_{\gamma}}-\delta_{A \gamma}
\end{array}\right]\right\}^{\prime}+\left[\begin{array}{c}
F_{A B \alpha} \\
F_{A B \beta} \\
F_{A B \gamma}
\end{array}\right] \\
& {\left[\begin{array}{l}
S_{A B \alpha} \\
S_{A B \beta} \\
S_{A B \gamma}
\end{array}\right]=K_{0}\left\{\left[\begin{array}{ccc}
0 & \lambda^{\prime \prime}{ }_{22} k_{\beta} & 0 \\
-\lambda^{\prime \prime}{ }_{11} k_{\alpha} & 0 & -2 \lambda_{31} k_{\alpha} \\
0 & \lambda^{\prime \prime}{ }_{23} k_{\beta} & 0
\end{array}\right]\left[\begin{array}{c}
\theta_{A \alpha} \\
\theta_{A \beta} \\
\theta_{A \gamma}
\end{array}\right]+\left[\begin{array}{ccc}
0 & \lambda^{\prime \prime}{ }_{22} k_{\beta} & 0 \\
-\lambda^{\prime \prime}{ }_{11} k_{\alpha} & 0 & 2 \lambda_{31} k_{\alpha} \\
0 & -\lambda^{\prime \prime}{ }_{23} k_{\beta} & 0
\end{array}\right]\left[\begin{array}{c}
\theta_{B \alpha} \\
\theta_{B \beta} \\
\theta_{B \gamma}
\end{array}\right]\right.} \\
& \left.-\frac{1}{L}\left[\begin{array}{ccc}
2 \lambda^{\prime \prime}{ }_{22} k_{\beta} & 0 & 0 \\
0 & 2 \lambda^{\prime \prime}{ }_{11} k_{\alpha} & 0 \\
0 & 0 & \lambda_{n} k_{n}
\end{array}\right]\left[\begin{array}{c}
\delta_{B \alpha}-\delta_{A \alpha} \\
\delta_{B \beta}-\delta_{A \beta} \\
\delta_{B \gamma}-\delta_{A \gamma}
\end{array}\right]\right\}+\left[\begin{array}{c}
G_{A B \alpha} \\
G_{A B \beta} \\
G_{A B \gamma}
\end{array}\right]
\end{aligned}
$$

と一般的に表わすととができるようになる。また、B点における、モーメントおよび力の釣合は、

$$
\begin{array}{ll}
M_{B A \alpha}=-\left(M_{A B \alpha}+L S_{A B_{\beta}}+\bar{M}_{\alpha}\right), & S_{B A \alpha}=-\left(S_{A B \alpha}+\bar{S}_{\alpha}\right) \\
M_{B A \beta}=-\left(M_{A B \beta}-L S_{A B \alpha}+\bar{M}_{\beta}\right), & S_{B A \beta}=-\left(S_{A B_{\beta}}+\bar{S}_{\beta}\right) \\
M_{B A_{\gamma}}=-\left(M_{A B_{\gamma}}+\bar{M}_{\gamma}\right), & S_{B A_{\gamma}}=-\left(S_{A B_{\gamma}}+\bar{S}_{\gamma}\right)
\end{array}
$$

と与えられる。最後の項は中間荷重による影響量である。これょり、B端の材端モーメントおよび材端力も同様に次 のように表わすととができる。

$$
\begin{aligned}
& {\left[\begin{array}{l}
M_{B A \alpha} \\
M_{B A \beta} \\
M_{B A \gamma}
\end{array}\right]=K_{0}\left\{\left[\begin{array}{ccc}
\lambda_{11} k_{\alpha} & 0 & -\lambda_{31} k_{\alpha} \\
0 & \lambda_{22} k_{\beta} & 0 \\
-\lambda_{31} k_{\alpha} & 0 & \lambda_{33} k_{\gamma}
\end{array}\right]\left[\begin{array}{c}
\theta_{B \alpha} \\
\theta_{B \beta} \\
\theta_{B \gamma}
\end{array}\right]+\left[\begin{array}{ccc}
\lambda_{11}^{\prime} k_{\alpha} & 0 & \lambda_{31} k_{\alpha} \\
0 & \lambda^{\prime}{ }_{22} k_{\beta} & 0 \\
-\lambda_{31} k_{\alpha} & 0 & -\lambda_{33} k_{\gamma}
\end{array}\right]\left[\begin{array}{l}
\theta_{A \alpha} \\
\theta_{A \beta} \\
\theta_{A \gamma}
\end{array}\right]\right.} \\
& \left.-\frac{1}{L}\left[\begin{array}{ccc}
0 & -\lambda^{\prime \prime}{ }_{11} k_{\alpha} & 0 \\
\lambda^{\prime \prime}{ }_{22} k_{\beta} & 0 & -\lambda^{\prime \prime}{ }_{23} k_{\beta} \\
0 & 2 \lambda_{31} k_{\alpha} & 0
\end{array}\right]\left[\begin{array}{c}
\delta_{B \alpha}-\delta_{A \alpha} \\
\delta_{B \beta}-\delta_{A \beta} \\
\delta_{B \gamma}-\delta_{A \gamma}
\end{array}\right]\right\}+\left[\begin{array}{c}
F_{B A \alpha} \\
F_{B A \beta} \\
F_{B A \gamma}
\end{array}\right] \\
& {\left[\begin{array}{c}
S_{B A \alpha} \\
S_{B A \beta} \\
S_{B A \gamma}
\end{array}\right]=-\frac{K_{0}}{L}\left\{\left[\begin{array}{ccc}
0 & \lambda^{\prime \prime \prime}{ }_{22} k_{\beta} & 0 \\
-\lambda^{\prime \prime}{ }_{11} k_{\alpha} & 0 & -\lambda_{31} k_{\alpha} \\
0 & \lambda{ }^{\prime \prime} k_{\beta} & 0
\end{array}\right]\left[\begin{array}{c}
\theta_{A \alpha} \\
\theta_{A \beta} \\
\theta_{A \gamma}
\end{array}\right]+\left[\begin{array}{ccc}
0 & \lambda^{\prime \prime}{ }_{22} k_{\beta} & 0 \\
-\lambda^{\prime \prime}{ }_{11} k_{\alpha} & 0 & 2 \lambda_{31} k_{\alpha} \\
0 & -\lambda^{\prime \prime}{ }_{23} k_{\beta} & 0
\end{array}\right]\left[\begin{array}{c}
\theta_{B \alpha} \\
\theta_{B \beta} \\
\theta_{B \gamma}
\end{array}\right]\right.} \\
& \left.-\frac{1}{L}\left[\begin{array}{ccc}
2 \lambda^{\prime \prime}{ }_{22} k_{\beta} & 0 & 0 \\
0 & 2 \lambda^{\prime \prime}{ }_{11} k_{\alpha} & 0 \\
0 & 0 & \lambda_{n} k_{n}
\end{array}\right]\left[\begin{array}{c}
\delta_{B \alpha}-\delta_{A \alpha} \\
\delta_{B \beta}-\delta_{A \beta} \\
\delta_{B \gamma}-\delta_{A \gamma}
\end{array}\right]\right\}+\left[\begin{array}{c}
G_{B A \alpha} \\
G_{B A \beta} \\
G_{B A \gamma}
\end{array}\right]
\end{aligned}
$$

てれら(4)、（6)式の最後の項は中間荷重による影響であつて、いわりる固定端モーメントあるいは固定端力を示す ものとなる。また $\lambda_{11}$ 等の係数は部材の形状に上る剛性係数である。

て〉で、ベクトル量の成分を $\alpha \beta r$ 軸より $X Y Z$ 軸党変換すると、固定座標 $X Y Z$ に対して一般に、 


$$
\begin{aligned}
& {\left[M_{A B}\right]=K_{0}\left\{\left[a_{A B}\right]\left[\theta_{A}\right]+\left[b_{A B}\right]\left[\theta_{B}\right]-\frac{1}{L}\left[f_{A B}\right]\left[\delta_{B}-\delta_{A}\right]\right\}+\left[F_{A B}\right]} \\
& {\left[M_{B A}\right]=K_{0}\left\{\left[b_{B A}\right]\left[\theta_{A}\right]+\left[a_{B A}\right]\left[\theta_{B}\right]-\frac{1}{L}\left[f_{B A}\right]\left[\delta_{B}-\delta_{A}\right]\right\}+\left[F_{B A}\right]} \\
& {\left[S_{A B}\right]=\frac{K_{0}}{L}\left\{\left[d_{A B}\right]\left[\theta_{A}\right]+\left[d_{B A}\right]\left[\theta_{B}\right]-\frac{1}{L}\left[g_{A B}\right]\left[\delta_{B}-\delta_{A}\right]\right\}+\left[G_{A B}\right]} \\
& {\left[S_{B A}\right]=\frac{K_{0}}{L}\left\{-\left[d_{A B}\right]\left[\theta_{A}\right]-\left[d_{B A}\right]\left[\theta_{B}\right]+\frac{1}{L}\left[g_{B A}\right]\left[\delta_{B}-\delta_{A}\right]\right\}+\left[G_{B A}\right]}
\end{aligned}
$$

と〉に[M $\left.M_{A B}\right]$ 等の列行列は、それぞれ $M_{A B}$ 等のベクトルの $X Y Z$ 軸光の成分 $M_{A B X}, M_{A B Y}, M_{A B Z}$ 等により 表わされるもので $\left[M_{A B}\right]=\left[\begin{array}{c}M_{A B X} \\ M_{A B Y} \\ M_{A B Z}\end{array}\right]$ 等という内容を示すものとする。

また $\left[a_{A B}\right] \cdots \cdots \cdots \cdot \ldots\left[g_{B A}\right]$ 等の部材の剛性と形状に関する係数は、 $\alpha \beta \gamma$ 軸に関する成分より、XYZ軸に関する成分に 変換する行列 $\left[\begin{array}{lll}l_{\alpha} & l_{\beta} & l_{\gamma} \\ m_{\alpha} m_{\beta} m_{\gamma} \\ n_{\alpha} n_{\beta} n_{\gamma}\end{array}\right]=\left[\Delta_{A B}\right]$ とその逆行列 $\left[\Delta_{A B^{-1}}\right]$ を缓入するととにより

$$
\begin{aligned}
& {\left[a_{A B}\right]=\left[\Delta_{A B}\right]\left[\begin{array}{ccc}
\lambda_{11} k_{\alpha} & 0 & \lambda_{31} k_{\alpha} \\
0 & \lambda_{22} k_{\beta} & 0 \\
\lambda_{31} k_{\alpha} & 0 & \lambda_{33} k_{\gamma}
\end{array}\right]\left[\Delta_{A B^{-1}}\right]} \\
& {\left[b_{A B}\right]=\left[\begin{array}{c}
\Delta_{A B}
\end{array}\right]\left[\begin{array}{ccc}
\lambda^{\prime}{ }_{11} k_{\alpha} & 0 & -\lambda_{31} k_{\alpha} \\
0 & \lambda^{\prime}{ }_{22} k_{\beta} & 0 \\
\lambda_{31} k_{\alpha} & 0 & -\lambda_{33} k_{\gamma}
\end{array}\right]\left[\Delta_{A B^{-1}}\right]} \\
& {\left[f_{A B}\right]=\left[\Delta_{A B}\right]\left[\begin{array}{ccc}
0 & -\lambda^{\prime \prime}{ }_{11} k_{\alpha} & 0 \\
\lambda^{\prime \prime}{ }_{22} k_{\beta} & 0 & \lambda^{\prime \prime}{ }_{23} k_{\beta} \\
0 & -2 \lambda_{31} k_{\alpha} & 0
\end{array}\right]\left[\Delta_{A B}{ }^{-1}\right]} \\
& {\left[d_{A B}\right]=\left[\begin{array}{c}
\Delta_{A B} \\
\Delta
\end{array}\right]\left[\begin{array}{ccc}
0 & \lambda^{\prime \prime}{ }_{22} k_{\beta} & 0 \\
-\lambda^{\prime \prime}{ }_{12} k_{\alpha} & 0 & -2 \lambda_{31} k_{\alpha} \\
0 & \lambda^{\prime \prime}{ }_{23} k_{\beta} & 0
\end{array}\right]\left[\Delta_{A B}{ }^{-1}\right]}
\end{aligned}
$$

$\left[a_{B A}\right]=\left[\Delta_{A B}\right]\left[\begin{array}{ccc}\lambda_{11} k_{\alpha} & 0 & -\lambda_{31} k_{\alpha} \\ 0 & \lambda_{22} k_{\beta} & 0 \\ -\lambda_{31} k_{\alpha} & 0 & \lambda_{33} k_{\gamma}\end{array}\right]\left[\Delta_{A B^{-1}}\right]$ $\left[b_{B A}\right]=\left[\Delta_{A B}\right]\left[\begin{array}{ccc}\lambda_{11}^{\prime} k_{\alpha} & 0 & \lambda_{31} k_{\alpha} \\ 0 & \lambda^{\prime}{ }_{22} k_{\beta} & 0 \\ -\lambda_{31} k_{\alpha} & 0 & -\lambda_{33} k_{\gamma}\end{array}\right]\left[\Delta_{A B^{-1}}\right]$ $\left[f_{B A}\right]=\left[\Delta_{A B}\right]\left[\begin{array}{ccc}0 & -\lambda^{\prime \prime}{ }_{11} k_{\alpha} & 0 \\ \lambda^{\prime \prime}{ }_{22} k_{\beta} & 0 & -\lambda^{\prime \prime}{ }_{23} k_{\beta} \\ 0 & 2 \lambda_{31} k_{\alpha} & 0\end{array}\right]\left[\Delta_{A B}{ }^{-1}\right]$ $\left[d_{B A}\right]=\left[\Delta_{A B}\right]\left[\begin{array}{ccc}0 & \lambda^{\prime \prime}{ }_{22} k_{\beta} & 0 \\ -\lambda^{\prime \prime}{ }_{11} k_{\alpha} & 0 & 2 \lambda_{31} k_{\alpha} \\ 0 & -\lambda^{\prime \prime}{ }_{23} k_{\beta} & 0\end{array}\right]\left[\Delta_{A B}{ }^{-1}\right]$ および $\left[g_{A B}\right]=\left[g_{B A}\right]=\left[\begin{array}{c}\Delta_{A B} \\ \end{array}\right]\left[\begin{array}{ccc}2 \lambda^{\prime \prime}{ }_{22} k_{\beta} & 0 & 0 \\ 0 & 2 \lambda^{\prime \prime}{ }_{11} k_{\alpha} & 0 \\ 0 & 0 & \lambda_{n} k_{n}\end{array}\right]\left[\Delta_{A B}{ }^{-1}\right]$ となる。

こ〉に $l_{\alpha} m_{\alpha} n_{\alpha}$ は $\alpha$ 軸の $X Y Z$ 軸えの方向余弦で、 $\beta$ お よびrのサフィックス法それぞれ $\beta$ 軸および 余弦を示すをのとする。乙れより $\left[a_{A B}\right],\left[a_{B A}\right]$ および $\left[g_{A B}\right]$ は対称行列で、 $\left[b_{A B}\right],\left[f_{A B}\right],\left[f_{B A}\right]$, と $\left[b_{B A}\right]$, $\left[d_{A B}\right],\left[d_{B A}\right]$ とはそれぞれ随伴行列となるととがわか る。またとれは Maxwell の相反作用の定理の示す当然 の結果でもある。

これら係数行列中の剛性係数の間には、

$\lambda^{\prime \prime}{ }_{11}=\lambda_{11}+\lambda_{11}^{\prime}, \quad \lambda^{\prime \prime}{ }_{22}=\lambda_{22}+\lambda_{22}^{\prime} \quad$ の関係があり、 独立の $\lambda_{11}, \lambda^{\prime}{ }_{11}, \lambda_{31}, \lambda_{33}$ を $\tau_{\alpha}=1$ および 4 の場合につい て、 $\lambda_{22}, \lambda_{22}^{\prime}, \lambda^{\prime \prime}{ }_{23}, \lambda_{n}$ の值を $\frac{I_{\beta 1}}{A L^{2}}=\frac{1}{1200}$ おるび $\frac{1}{4800}$ に ついて図示すると第 3 図〜第7 図に示すようになる。て れらは前にも述べたように、断面の形状と円弧の開角に 上つて決まるわけで、当然 $\Phi=0$ の場合が等断面值線材 を表わすことになる。

\section{§3. 円孤部材における荷重項について}

円弧部材における荷重項を一般的に取报うととは非常 に煩杂䧴である。各種の荷重状沿に対して諸係数を整備す べきであるが、と〉では自重の様な等分布荷重を受ける
場合の荷重の係数を参考にあげるに止める。 $w_{X}, w_{Y}$, $w_{Z}$ をそれぞれ荷重強度の成分とすれぱ、等分布荷重に 対して、

$$
\begin{aligned}
& {\left[F_{A B}\right]=\left[\Delta_{A B}\right]\left[\begin{array}{ccc}
0 & \nu_{12} & 0 \\
-\nu_{21} & 0 & -\nu_{23} \\
0 & \nu_{32} & 0
\end{array}\right]\left[\Delta_{A B^{-1}}\right]\left[\begin{array}{l}
w_{X} \\
w_{Y} \\
w_{Z}
\end{array}\right]^{L^{2}}} \\
& {\left[F_{B A}\right]=\left[\Delta_{A B}\right]\left[\begin{array}{ccc}
0 & -\nu_{12} & 0 \\
\nu_{21} & 0 & \nu_{23} \\
0 & \nu_{32} & 0
\end{array}\right]\left[\Delta_{A B^{-1}}\right]\left[\begin{array}{l}
w_{X} \\
w_{Y} \\
w_{Z}
\end{array}\right] L^{L^{2}}} \\
& {\left[G_{A B}\right]=\left[\Delta_{A B}\left[\begin{array}{ccc}
-\nu_{11}^{\prime} & 0 & \nu_{13}^{\prime} \\
0 & -\nu_{22}^{\prime} & 0 \\
\nu_{31}^{\prime} & 0 & -\nu_{33}^{\prime}
\end{array}\right]\left[\Delta_{A B^{-1}}\right]\left[\begin{array}{c}
w_{X} \\
w_{Y} \\
w_{Z}
\end{array}\right]^{L}\right.}
\end{aligned}
$$

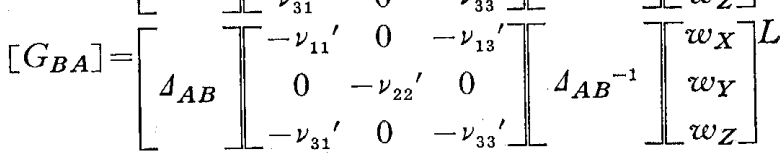

と表わされる。て〉に $\nu_{12}$ 等は開危と断面形状によつて

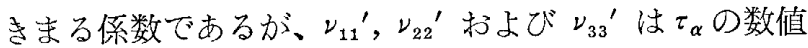
に無関係で $\nu_{11}{ }^{\prime}=\nu_{22}{ }^{\prime}=\nu_{33}{ }^{\prime}$ となり、 $\nu_{32}$ は $\tau_{\alpha}=1$ および 4.また $\nu_{23}$ および $\nu_{13}{ }^{\prime}$ は $\frac{I_{\beta 1}}{A L^{2}}$ が $\frac{1}{1200}$ でも $\frac{1}{4800}$ でも 殆んど差異を示さないので一つの曲線で示すと、 $\nu_{12}$ 等 の係数は第 8 図と第 9 図に示すようになる。 


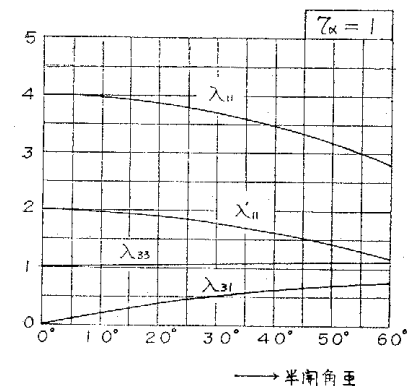

第 3 図 円弧部材の岡性係数表・その 1

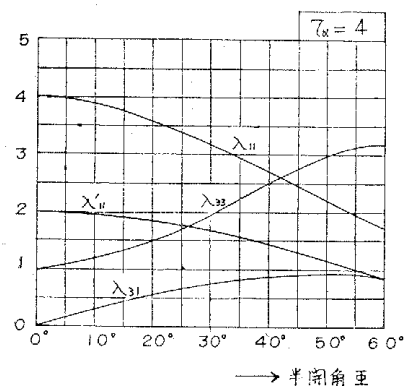

第 4 図门弧部材の剛性係数表・その 2

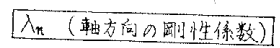

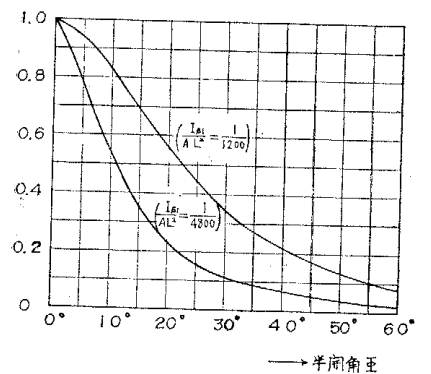

第 7 図 円柘部材の剛性俰数表・その 5

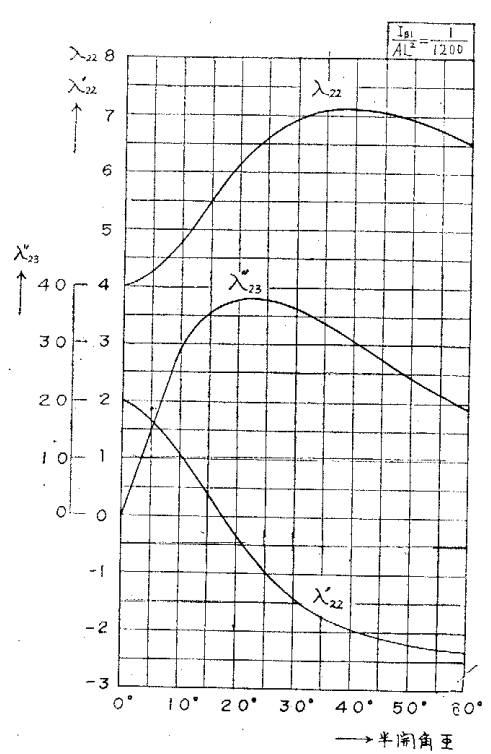

第 5 図 円弧部材の岡性係数表·その3

等分布荷重のとき

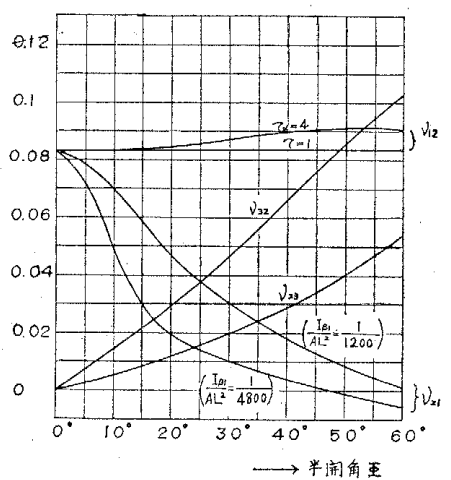

第 8 図固定端モーメント用係数図表

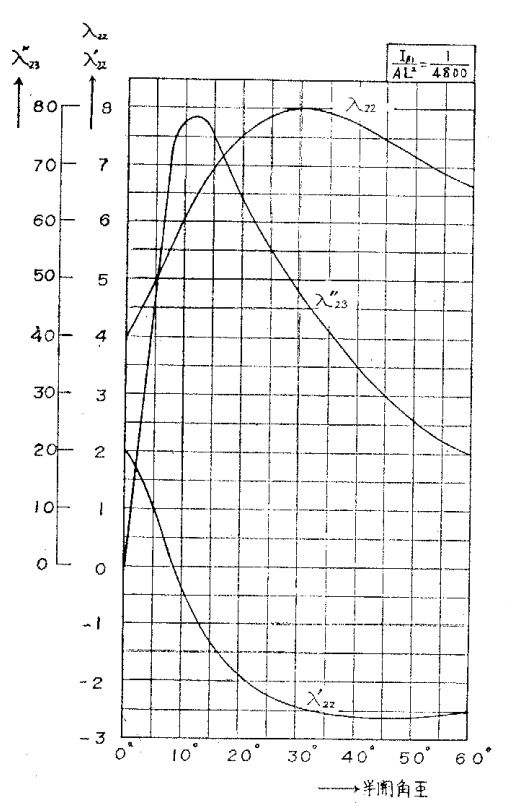

第 6 図 円弧部材の剛性係数表・艺の 4 等分布荷重口天司

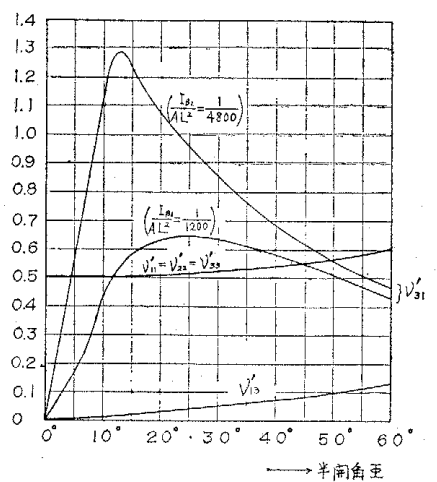

第 9 図 固定端力用绿数図表
\$4. 計算例 との三次元㜔角法公式の適用虫在来 の暁角法と同様で、各節点におけるモーメントと力の验

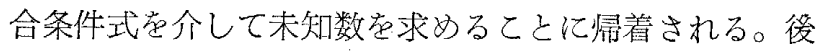
者の力の釣合式は部材の長さが変化しない子芳えると き、いわ㠹ん力方程式となるものである。この方法 を理解して頂くため潐備した計算例は紙面の都合で他 の機会に鸣ずり省略した。

§5. むすび本論文では三次元㧥角法の具体的な 例として、円弧部材含含立体ラーメンの解法を述べた が、この方沾仗一般の任意形状の曲線部材に対しても拡 㖘でき、ベクトル量を列行列で効応させ置換部材を考光 ると、その取报いは直線材と全く同様となる。そして共 通の固定座標について方程式在求めると、その条件式の
取披いは極めて容易となり、完全弾性体よりなり変形が 小さいと仮定できる場合には、任意形状の部材よりなる 立体骨組の解析す機械的に行うことができるようになる のは大きな利点であろう。最後にての諭文の図表の作成 を担当して戴いた、、明治大学学生佐藤卓、日本大学学生 宮崎慶二両君の多大の協力江感謝致します。

\section{[参考文献]}

1）牧野 稔 “立体フレームの解法に関する研究（その7) （任意部材の三次元撓角法の公式について）関東支部第 30 回研究発表会 昭和 36 年 6 月

2）平見静夫 “円弧材を含㗎棈の計算について”（軸方向 力、せえ断力、部材の曲率の影響を考无て場合) 日本建築学会研究報告 第 20 号 昭利 27 年 10 月 